\title{
Inhalt des VIII. Bandes
}

\section{Romanistische Abtheilung.}

Gh i appelli, L., Neue Bemerkungen über die Pistoieser Glosse zum Justinianischen Codex . . . . . . . . . . . . . . . 86

Exner, A., Die imaginäre Gewalt im altrömischen Besitzstörungsverfahren . . . . . . . . . . . . . . . . . . . 167

Geib, O., Actio fiduciae und Realvertrag . . . . . . . . 112

Kr üger, P., Ueber die Verwendung von Papyrus und Pergament für die juristische Litteratur der Römer . . . . . . . . 76

-, - Bemerkungen zu Schirmers Replik in Sachen des linum testamenti incisum . . . . . . . . . . . . . . . . 109

Len el, O., Kritisches und Exegetisches . . . . . . . . . 195

Schirmer, Th., Replik in Sachen des limum testamenti incisum 99

—, -, Die angeblichen Interpolationen bei Scävola . . . . . 155

Zachariä von Lingenthal, E., Von den griechischen Bearbeitungen des Codex . . . . . . . . . . . . . . 1

—, -, Aus und zu den Quellen des römischen Rechts . . . . 206

Zum Wörterbuche der klassischen Rechtswissenschaft . . . . . 279

\section{Miscellen:}

Caillemer, E., Zur Pariser Handschrift des Tübinger Rechtsbuches Nr. 4917 . . . . . . . . . . . . . . . 260

Conrat, M., Zum Ashburnhamer Rechtsbuch . . . . . . 262

Gradenwitz, O., Zum Sprachgebrauche des prätorischen

Edikts . . . . . . . . . . . . . . . 201

Mommsen, Th., Eine Inschrift aus del Umgegend von Rom 248

\section{Litteratur:}

Demelius, Schiedseid und Beweiseid im römischen Givilprozesse 269 Besprochen von 0. Gradenwitz.

Landsberg, Iniuria und Beleidigung . . . . . . . . . . 265 Besprochen von E. Brunjenmeister.

Statuto dell' Istituto di Diritto Romano . . . . . . . . . 305 
